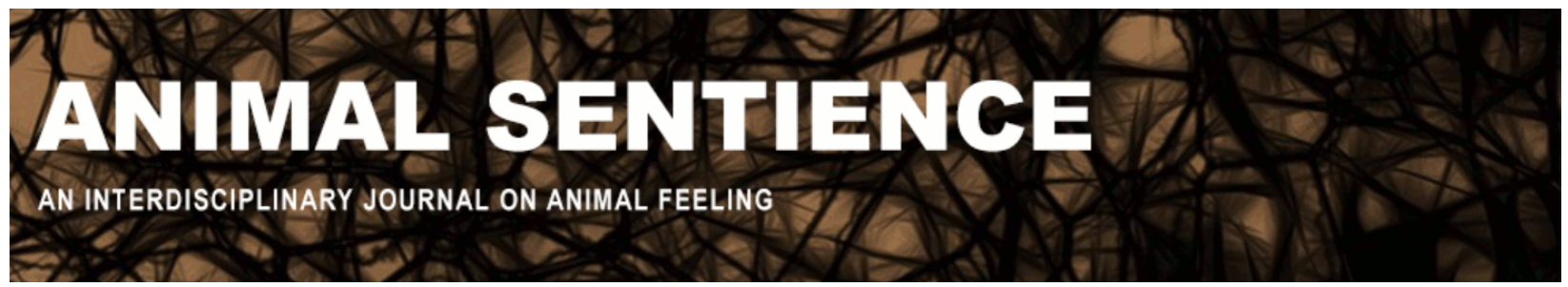

Adolphs, Ralph (2019) Using sheep psychology to guide sheep policy. Animal Sentience 25(14)

DOI: $10.51291 / 2377-7478.1447$

Date of submission: 2019-05-15

Date of acceptance: 2019-05-21

(c) (†)

This article has appeared in the journal Animal

Sentience, a peer-reviewed journal on animal

cognition and feeling. It has been made open access,

free for all, by WellBeing International and deposited

in the WBI Studies Repository. For more information,

please contact

wbisr-info@wellbeingintl.org.

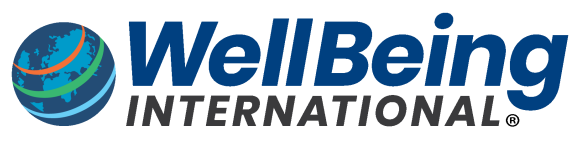

SOLUTIONS FOR PEOPLE, ANIMALS AND ENVIRONMENT 


\title{
Using sheep psychology to guide sheep policy
}

Commentary on Marino \& Merskin on Sheep Complexity

\author{
Ralph Adolphs \\ California Institute of Technology
}

\begin{abstract}
Marino \& Merskin's valuable review of the literature on sheep cognition shows how entrenched common views of these animals' mental lives are disputed by the research literature. Yet the evidence they muster faces three challenges that their target article does not discuss: (1) the behavioral tasks are strongly anthropocentric; (2) neuroscientific data are absent; and (3) applications are not discussed. I touch on all three of these here.
\end{abstract}

Ralph Adolphs is a social neuroscientist who studies emotions in humans. He is the Bren Professor of Psychology, Neuroscience, and Biology at the California Institute of Technology. Adolphs is the co-author of the book, The Neuroscience of Emotion: A New Synthesis, Princeton University Press, 2018. Website

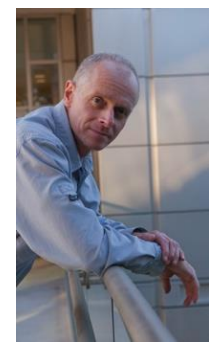

1. Understanding sheep through the lens of human psychology. Marino \& Merskin (2019) (M\&M) conclude that sheep minds are considerably more complex and sophisticated than commonly and historically thought, but it remains a little unclear how to interpret the data they review. I think the data surely underestimate the intelligence of sheep (a feeling shared by some of the other commentators, and for similar reasons; Brooks Pribac 2019, Pena-Guzman 2019). The reason is that essentially all of the tasks, and the corresponding psychological processes they are supposed to measure, have been invented by psychologists familiar with human rather than sheep psychology. There are at least three problems with this.

First, these tasks and processes are historically entrenched. It is likely that they will, in time, be superseded by processes better aligned with computational models and/or neuroscience data.

Second, they are thought up by human minds. Unless these humans are seasoned ethologists, it is likely that the entire psychological ontology, the corresponding inventory of tasks, and the interpretations of the data from sheep are all strongly anthropomorphic. (Vonk 2019 voices similar concerns in her commentary.)

Third, the tasks are highly artificial and fail to consider the actual natural behaviors and ecological niche of the sheep. I find it doubtful that cognitive inhibition, flexibility, planning, etc. (to pick just the first ones mentioned in M\&M's paper) are the best way to carve up the terrain. One could think of alternative ontologies. When more data-driven approaches to executive functions have actually been taken (in humans), processes don't exactly cluster according to the preconceived categories that psychologists have thought up (see Eisenberg et al. 2018 for an example). 
2. A place for neuroscience. Some of the other processes reviewed by $M \& M$ are perhaps less problematic in their ecological validity than what I noted above. Face perception, for example, clearly shows abilities that make some ecological sense. It is here that neuroscience data could also be mustered: it not only helps bridge the performance-competence gap, but insofar as it shows close similarities with human brain responses, it is an independent source of evidence for the mental lives of sheep. For example, there is the finding that cells in sheep brains in regions involved in face processing respond to the size of the horns on sheep, a signal for social dominance. In fact, sheep brains respond to faces in a way that is similar in many respects to how primate brains respond to faces: neurons encode face identity, familiarity, and social information (see Tate et al. 2006 for review). Noninvasive brain imaging (functional MRI) has been applied to dogs (Cook et al. 2018), adding to our knowledge of the minds of those animals; there is no reason similar data could not be acquired in sheep.

We understand perhaps the least about sheep emotions, as it is unclear how even to measure these, but it seems apparent that the way we currently infer them is strongly anthropomorphic. I for one have no doubt that sheep have emotions, but we need much better behavioral criteria to figure out which emotions these are (Adolphs 2017). Both emotion and personality are strong components of social behavior (indeed, M\&M already have social behavior categories under their "emotion" section), and a better understanding of these psychological domains will come from a better observation of real-world social behavior together with neuroscience data.

3. What do we do next? Notwithstanding the above limitations, a relatively persuasive picture does emerge from the literature review that M\&M provide. Sheep have minds of considerable sophistication. At a minimum, it seems fair to say that they are so complex that we currently do not understand them well at all. At a maximum, we may need to consider their mental complexity on a par with our own, once we do understand them well enough. What follows from this?

Given the above picture, the risk-averse stance would be to allow sheep some of the rights of persons until proven otherwise (such as the habeas corpus cases that have been won in recent years, mostly for great apes; The Economist 2018). Going further requires more specific arguments. In her commentary, Vonk (2019) expresses the widely shared view that the capacity for suffering is the most important criterion. It would hence follow that scientific evidence bearing on this question is most relevant (emotions, personalities, etc.); but one could imagine arguments based on other capacities as well. (As in humans, the capacity for complex psychological lives, even if only positive, surely has intrinsic value.) Woodruff (2019) is perhaps the most specific in his commentary, arguing for particular changes in policy. Like the legal arguments, these will need to be linked to specific types of scientific evidence.

The biggest challenge, then, is perhaps not just gathering more and better data on sheep psychology, but some sort of guiding inventory of the kinds of evidence worth looking for, in the sense that they are what we need if we actually want to do anything about the welfare of sheep. 


\section{References}

Adolphs, R. (2017) Dogs consciously experience emotions: the question is, which?. Animal Sentience 14(2).

Brooks Pribac, T. (2019) Positive sentience is underrated. Animal Sentience 25(11)

Cook, P., Prichard, A., Spivak, M., and Berns, G. S. (2018) Jealousy in dogs? Evidence from brain imaging. Animal Sentience 22(1)

Eisenberg, I. W., Bissett, P., Enkavi, A. Z., Li, J., MacKinnon, D., Marsch, L., and Poldrack, R. (2018) Uncovering mental structure through data-driven ontology discovery. PsyArxiv.

Marino, L., and Merskin, D. (2019) Intelligence, complexity, and individuality in sheep. Animal Sentience 25(1)

Pena-Guzman, D. M. (2019) Casting a sheep's eye on science. Animal Sentience 25(6)

Tate, A. J., Fischer, H., Leigh, A. E., and Kendrick, K. M. (2006) Behavioral and neurophysiological evidence for face identity and face emotion processing in animals. Philosophical Transactions of the Royal Society Series B 361: 2155-2172.

The Economist, Dec. 18, 2018. Gradually, nervously, courts are granting rights to animals. Vonk, J. (2019) Pulling the wool from our eyes. Animal Sentience 25(3)

Woodruff, M. L. (2019) Smart sheep need more protection. Animal Sentience 25(9) 